\title{
Capitalismo de vigilância e tecnopolítica: os direitos fundamentais de privacidade e liberdade de expressão sob ataque
}

\author{
Recebido: 25 de outubro de 2020 • Aprovado: 5 de março de 2021 \\ https://doi.org/10.22395/ojum.v20n42a2 1
}

\begin{abstract}
José Adércio Leite Sampaio
Pontifícia Universidade Católica de Minas Gerais Escola Superior Dom Helder Câmara (ESDHC/MG)

Belo Horizonte, Brasil joseadercio.contato@gmail.com https://orcid.org/0000-0002-9452-4811

Meire Furbino

Pontifícia Universidade Católica de Minas Gerais

Belo Horizonte, Brasil meirefurbino@gmail.com https://orcid.org/0000-0003-4463-9554

Lavinia Assis Bocchino

Pontifícia Universidade Católica de Minas Gerais Belo Horizonte, Brasil lavinia9assis@gmail.com https://orcid.org/0000-0003-1295-3442
\end{abstract}

\section{RESUMO}

Discorre-se, no presente artigo, sobre as ameaças que as empresas de tecnologia da informação podem apresentar aos direitos fundamentais e ao constitucionalismo, diante da captura de dados, por particulares, com fins monetários, sem resposta contundente do poder estatal. Ressalta-se a vulnerabilidade das pessoas e a influência comportamental levada a efeito por meio de algoritmos e outros mecanismos ligados à internet. Aborda-se, com base em pesquisa documental, bibliográfica e normativa, o 'capitalismo de vigilância', proposto por Shoshana Zuboff, a garantia da privacidade e a transparência das empresas. Identifica-se um modo novo de acumulação de capital e a inadequação dos mecanismos tradicionais de regulamentação para combater seus excessos. Ao final, aponta-se para a necessidade de uma educação digital efetiva como solução à manipulação digital e combate à vulnerabilidade dos usuários - e de seus direitos.

Palavras-chave: democracia; constitucionalismo; direitos fundamentais; direito à privacidade e à liberdade de expressão; capitalismo de vigilância; educação digital. 


\section{Surveillance and Technopolitical Capitalism: the Fundamental Rights of Privacy and Freedom of Expression Under Attack}

\section{ABSTRACT}

This article discusses the threats that information technology companies can present to fundamental rights and constitutionalism, in the face of data capture, by individuals for monetary purposes and without a forceful response from state power. We highlight the vulnerability of people and the behavioral influence carried out through algorithms and other mechanisms connected to the internet. Based on documentary, bibliographic and normative research, the 'surveillance capitalism' proposed by Shoshana Zuboff, the guarantee of privacy and the transparency of companies are approached. A new way of accumulating capital is identified as well as the inadequacy of traditional regulatory mechanisms to combat its excesses. In the end, it points towards the need for an effective digital education as a solution to digital manipulation and to combat the vulnerability of users and their rights.

Keywords: Democracy; constitutionalism; fundamental rights; right to privacy and freedom of speech; surveillance capitalism, digital education.

\section{Capitalismo de vigilancia y tecnopolítica: los derechos fundamentales de privacidad y libertad de expresión bajo ataque RESUMEN}

Se discurre, en el presente artículo, sobre las amenazas que las empresas de tecnología de la información pueden presentar a los derechos fundamentales y al constitucionalismo, ante la captura de datos, por particulares, con fines monetarios, sin respuesta contundente de parte del poder estatal. Cabe resaltar la vulnerabilidad de las personas y la influencia del comportamiento llevada a efecto por medio de algoritmos y otros mecanismos relacionados con internet. Se aborda, con base a la pesquisa documental, bibliográfica y normativa, el 'capitalismo de vigilancia', propuesto por Shoshana Zuboff, garantizar la privacidad y la transparencia de las empresas. Se identifica un nuevo modo de acumulación de capital y la inadecuación de mecanismos tradicionales de reglamentación para combatir sus excesos. Al concluir, se indica la necesidad de una educación digital efectiva como solución a la manipulación digital y el combate a la vulnerabilidad de los usuarios y sus derechos.

Palabras clave: Democracia; Constitucionalismo; Derechos fundamentales; Derechos a la privacidad y a la libertad de expresión; Capitalismo de vigilancia; Educación digital. 


\section{INTRODUÇÃO}

Este artigo é originário de atividade acadêmica desenvolvida pelos autores no âmbito da pós-graduação sctrito sensu, com ênfase em direito constitucional, da Pontifícia Universidade Católica de Minas Gerais/Brasil, e inicia pesquisa sobre os riscos de violação aos direitos fundamentais - da privacidade e da liberdade de expressão - em tempos de preponderância do denominado capitalismo de vigilância e da tecnocracia.

A tecnologia da informação tem alterado a economia e os processos identitários e de socialização. As plataformas de mídias financiariam os dados dos usuários ao tratarem a extração e monetização dos dados como uma forma de capital. O acúmulo massivo desses dados, para análise e interpretação, é denominado de Big Data, e se constitui no componente fundamental para melhor compreensão do funcionamento acerca da moderna política econômica: o 'capitalismo de vigilância'.

Esse redemoinho tem causado sérias dúvidas sobre a integridade do sistema de direitos e mesmo da democracia. Em princípio, a oferta era comodidade de aplicativos e utilitários virtuais a custo zero. Os usuários não se davam conta de que, na verdade, havia um custo alto embutido na oferta: eles eram o produto e a fonte de lucros. A empresa Google, pioneiramente, usou os rastros dos sites pesquisados pelos usuários, considerados por muitos lixos virtuais, e os transformou em mercadoria altamente rentável. Seguindo seus passos, outras empresas adotaram semelhante política de exploração de dados.

As plataformas imputam ao governo a responsabilidade por limitar, em alguma medida, a liberdade dos usuários, enquanto elas se postam como veículos de acesso dos usuários a esse direito. Os próprios Termos de Uso e Serviço das plataformas demonstram como os usuários estão vulneráveis às regras que essas empresas impõem, sem que tenham voz ou proteção do poder público.

Certo é que, no mundo da comunicação digital, desde as redes e mídias sociais à internet das coisas (IoT), a manipulação dos indivíduos em sua liberdade de escolha, a violação de sua 'privacidade' e a veiculação de fake news têm colocado o sistema constitucional com seus mecanismos de proteção dos direitos e da democracia em risco. Esse cenário demanda do constitucionalismo moderno respostas que aparentemente ainda não foram dadas.

No presente estudo, analisa-se os aspectos gerais que levaram a esse estado de coisas: o desenvolvimento da tecnopolítica que se auto definiu com um novo fazer capitalista, aparentemente refratário aos modelos tradicionais de regulamentação estatal.

Aplicou-se o método normativo-dedutivo, fundado em revisão bibliográfica, perpassando pela abordagem da análise e da utilização de dados pessoais, expostos nas redes sociais, por meio das plataformas digitais, pela modulação de 
comportamentos e pela manipulação, por meio das empresas de tecnologia da informação, modificando padrões e alterando condutas.

Iniciou-se o estudo com a abordagem da tecnopolítica e a utilização das redes sociais, para pontuar os dilemas atuais, provenientes da extração de dados e a obtenção de vantagens financeiras por meio deles. No segundo capítulo, buscou-se apontar as questões referentes ao chamado capitalismo de vigilância e sua influência na garantia de direitos fundamentais. No terceiro capítulo avançou-se sobre o risco decorrente do mundo virtual, especificamente sobre os direitos de liberdade de expressão e de privacidade, para concluir pela necessidade de mecanismos de emancipação dos usuários, a exemplo da adoção de alfabetização ou educação digital dos usuários com vistas à conscientização do uso racional das redes e a imprescindível preservação dos direitos fundamentais.

\section{TECNOPOLÍTICA E REDES SOCIAIS: DILEMAS DA CONTEMPORANEIDADE}

Em curto período, surge uma nova fonte de renda e de riqueza, comparável, por alguns, ao petróleo (ouro negro): os dados pessoais, obtidos nas redes sociais e mercantilizados em ambiente virtual, que movimentam a economia da informação. A extração desses dados, gratuitamente, na maioria das vezes, iniciou-se de forma silente e sem despertar nenhuma atenção. Esse nicho de mercado, até então desconhecido, foi amplamente explorado pela empresa Google e, só mais tarde, outras grandes empresas desse segmento seguiram por seus passos. Não por acaso, tais empresas acumulam as maiores fortunas no mundo atual. Elas monetizam um capital fictício, antes formado por letras de câmbio, ações, títulos da dívida pública, com a criação do papel moeda e suas derivações no mundo financeiro, agora substituído por nada mais nada menos do que informações, que passam por uma espécie de processo alquímico, convertendose no ouro negro moderno (Binswanger, 2011). Diferentemente do ouro negro, as informações não se esgotam no seu uso. Ao contrário, produzem mais informações e matéria-prima para a alquimia econômica.

A financeirização da vida real se dá por meio da análise dos hábitos cotidianos, com aporte em tecnologias digitais que os transformam em dados e, a partir daí, em mercadorias digitais. Rafael Grohmann (2019) aponta para a importância da comunicação, no meio virtual, como forma de circulação do capital e, consequentemente, de seus signos. Para ele "tanto a circulação de mercadorias quanto a circulação de sentidos fazem parte do regime de signos linguísticos" que produzem uma comunidade de valor e que possibilitam a "sedimentação de uma gramática do capital imposta a todos como única possibilidade de sobreviver no mundo" (Grohmann, 2019, p. 103). Dessa forma, a comunicação funciona como um órgão (braço) da financeirização, que, conectada à tecnologia, produz a midiatização e a circulação da chamada ideologia desenvolvida no Vale do Silício (Grohmann, 2019). 
As transações financeiras demonstram a circulação monetária nas operações de compras, vendas e serviços, facilitados pela utilização de aplicativos (app), plataformas, programas, entre outros meios de tráfico de valores, a significar que "a circulação de capital atua conjuntamente à circulação de plataformas, força de trabalho e sentidos" (Grohmann, 2019, p. 104). Segundo o autor, a "dataficação e a plataformização envolvem não só a crescente centralidade dos dados na vida cotidiana, mas a circulação de sentidos sobre plataformas, dados, algoritmos e inteligência artificial em processos comunicacionais e produtivos, envoltos nas interações cotidianas e nas instituições" (Grohmann, 2019, p. 108). Acrescenta, ainda, que há uma simbiose entre a "circulação do capital e sua dimensão comunicacional", de forma que "circular os sentidos sobre dados, algoritmos e inteligência artificial é sedimentar sentidos e produzir/fazer circular capital em torno desses mesmos elementos" (Grohmann, 2019, pp. 108-109). Essa "cristalização dos sentidos de neutralidade, objetividade e infalibilidade" dos dispositivos digitais utilizados significa uma "retórica envolvida no data gaze, como uma caixa preta" e conduz à afetação "[das] corporações, [do] Estado e [da] a sociedade civil" (Grohmann, 2019, pp. 108-109).

Algoritmos, segundo Débora Machado (2018), podem ser entendidos como "uma série de instruções delegadas a uma máquina para resolver problemas pré-definidos" (p. 48) ou, mais especificamente, "são processos codificados para transformar dados de entrada e uma saída desejada, com base em cálculos especificados e estão presentes em praticamente todas as funções que executou na rede" (p. 48). A combinação de algoritmos permite identificar as informações relevantes daquelas que podem ser imprestáveis. Eles também possibilitam "a coleta e a análise massiva e automatizada de dados, o que os tornou tecnologias essenciais para o modelo de negócios das principais plataformas digitais utilizadas nos últimos anos" (Machado, 2018, p. 49). Portanto, o objetivo com o qual essas empresas utilizam os algoritmos passa distante da neutralidade. Segundo leciona Rob Kitchin (2017), eles se prestam "a criar valor de capital, para impulsionar um comportamento e estruturar preferências de uma certa forma; e para identificar, selecionar e classificar pessoas"1 (p. 5).

A esse processo se soma o aprendizado de máquinas, alcançado por meio de redes neurais artificiais, que imprime ganhos em escala e projeta um universo de possibilidades de contínua exploração dos recursos (Indolia, Goswami, Mishra, \& Asopa, 2018). As redes neurais "são técnicas computacionais que apresentam um modelo matemático inspirado na estrutura neural de organismos inteligentes e que adquirem conhecimento através da experiência" (Redes neurais artificiais, n. d., n. p.). Elas podem ter milhares de unidades de processamento e uma de suas principais características é o auto aprendizado, ou seja, a "habilidade de aprender de seu ambiente e com isso melhorar

No original: "to create value and capital; to nudge behaviour and structure preferences in a certain way; and to identify, sort and classify people". (Kitchin, 2017, p. 5). 
seu desempenho", o que é feito por meio de "processo iterativo de ajustes aplicado a seus pesos, o treinamento" (Redes neurais artificiais, n. d., n. p.).

Como se dá, então, a mineração desses dados e, uma vez obtidos, como são transformados em capital empresarial? Como são manejados para produzir cada vez mais riquezas?

\subsection{Extração de dados e sua monetização}

A chamada economia digital se vale de tecnologias da informação como as plataformas digitais e a internet das coisas (IoT), que utilizam dados para operar no mundo virtual e atingir objetivos próprios do mundo real, gerando valor e lucro. Todavia, dados não são sempre mercadorias, mas sim, uma forma de capital que permite a análise da natureza e dinâmica do capitalismo, no mundo digital (Sadowski, 2019). Quanto mais dados são extraídos e monetizados (na forma de capital), melhores resultados financeiros serão obtidos pelas empresas que atuam ativamente no setor, razão pela qual "quando os dados são tratados como uma forma de capital, o imperativo de coletar muitos dados a partir de muitas fontes intensifica práticas existentes de acumulação e leva à criação de novas"2 (Sadowski, 2019, p. 7).

Essa relação à política de dados, seu extrativismo e exploração capitalista, tem sido denominada de formas diversas, a depender de quem a analisa. Assim, os termos "capitalismo de vigilância (Foster e McChesney, 2014; Zuboff, 2018), "capitalismo informacional (Fuchs, 2010), capitalismo comunicativo (Dean, 2005), capitalismo de plataforma" (Srnicek, 2016) e "iCapitalism" (Duff, 2016)", dizem respeito à mesma temática, com abordagem diferenciada, mas que, por vezes, aportam a mesma conclusão (Sadowski, 2019, p. 2). Para Nick Srnicek (2016), por exemplo, os dados constituem a principal matéria-prima do capitalismo de plataforma, que faz suas operações nas plataformas digitais, nas quais é possivel extrair e controlar grandes quantidades de dados.

Sadowski (2019) percebe que o mundo, visto pela lente de dados, assume formas diferenciadas, a depender da influência comportamental exercida por aqueles que detêm o capital de dados e, nessa condição, promovem a relação poder/conhecimento, de forma que "conhecer o mundo é exercer poder sobre ele e exercer poder é conhecê-lo - examinar suas características e classificá-lo em categorias e normas, torná-lo legível e observável, excluir outras métricas e métodos de conhecê-lo"3 (p. 2).

A análise das características e sua categorização permite, então, a manipulação da vida cotidiana, de modo a alterar padrões, sugerir necessidades, impor transformações, em

2 No original: "When data is treated as a form of capital, the imperative to collect as much data, from as many sources, by any means possible intensifies existing practices of accumulation and leads to the creation of new ones." (Sadowski, 2019, p. 7).

3 No original: "to know the world is to exercise power over it and to exercise power is to know it - to examine its features and characteristics, to sort it into categories and norms, to render it legible and observable, to exclude other metrics and methods of knowing it" (Sadowski, 2019, p. 2). 
diferentes níveis e dimensões. Significa observar a vida cotidiana para dela extrair dados e, em seguida, devolver às comunidades outras informações - já lapidadas pelo detentor dos dados -, que alteram os comportamentos e induzem a uma nova realidade.

Essa prática é descrita por Natascha van der Zwan (2014) como "financeirização da vida cotidiana"4 (p. 110). O uso das tecnologias digitais transformou a vida social em mercadoria, na medida em que teve seu fluxo liberado e legitimado pelos discursos denominados por Rafael Grohmann (2019) de "signos do capital em circulação" (p. 102). Van der Zwan (2014) complementa que a análise da financeirização foi feita a partir do cotidiano das pessoas comuns (e não da elite), utilizando-se de imagens, textos, campanhas publicitárias, revistas, fontes abertas, enfim, que representavam a cultura dessas pessoas, seus hábitos, gostos e interesses. Tudo isso serve, ao fim e ao cabo, para o desenvolvimento de estratégias de comércio nas plataformas virtuais.

É nesse contexto que se opera a dataficação, a significar, segundo Grohmann (2019), "a crescente centralidade dos dados na vida cotidiana, afetando os processos comunicacionais" (p. 106), de modo que a sociabilidade atual "é formada por dados e algoritmos, como infraestruturas da comunicação" (p. 106). Mesmo em uma dimensão discursiva, "os signos nas mídias digitais também são dataficados" (Grohmann, 2019, p. 106). A circulação da comunicação nos ambientes digitais sempre deixa seus rastros e esses rastros digitais "são uma maneira de conformar a circulação comunicacional a partir da circulação de dados/circulação algorítmica" (Grohmann, 2019, pp. 106-107).

O historiador israelense Yuval Noah Harari (2016) denomina esse fluxo de dados como dataísmo, a significar uma espécie de religião, segundo a qual "[...] o universo consiste num fluxo de dados e o valor de qualquer fenômeno ou entidade é determinado por sua contribuição ao processamento de dados" (p. 370). Esse fluxo, para a 'seita', não deve ser interrompido ou obstado, pois a humanidade teria como 'vocação cósmica' criar os dados e permitir seu processamento, permitindo a inteira "liberdade de informação" (Harari, 2016, p. 385), entendida como o direito da informação circular livremente sem que seja impedida a movimentação dos dados.

Ainda que os nomes sejam diversos (dataísmo, dataficação e equivalentes), a singularidade fica por conta da importância dos dados e de sua exploração no mundo virtual, a influenciar os padrões da vida real e movimentar a economia informacional. A rede, então, é "a nova ideologia do capitalismo sem limites" (Lôbo; Morais, 2021, p. 256) e a disponibilização de dados pessoais, advertida ou inadvertidamente, é o preço pago pela utilização, em tese, gratuita, dos serviços disponíveis em plataformas e sítios eletrônicos.

Srnicek (2016, p. 43), como já referido, adota o termo capitalismo de plataforma e sustenta que as plataformas foram consideradas como "infraestruturas digitais que

4 No original: "financialization of everyday life" (Van Der Zwan, 2014, p. 110). 
possibilitam a interação entre dois ou mais grupos" ${ }^{\prime \prime}$. As plataformas são abastecidas por dados e configuram a versão moderna de exploração capitalista, conforme expõe Rafael Grohmann (2019): "os dados têm cumprido funções-chave, pois se colocam como infraestruturas digitais da circulação do capital" (p. 107). Para Grohmann (2019), a repetição do mantra "os dados são o novo petróleo" conduz à reflexão sobre a centralidade da exploração de dados no capitalismo contemporâneo: "tudo se passa como se o processo de circulação de dados fosse algo natural, como algo neutro, objetivo, acima de tudo, o que Van Dijck (2014) chama de ideologia do dataísmo e Beer (2018) nomeia como 'olhar de dados'" (p. 107).

No entanto, essa entronização dos dados ou sua elevação à condição de semideuses inquestionáveis, indicativas de como devem ser tomadas as decisões, podem ser consideradas novo paradigma científico. Grohmann (2019) assevera que "expressões como Big Data e algoritmos circulam no mundo social como mantras de reafirmações tecnológicas e empresariais, sinônimos de contemporaneidade e inovação, instituindo um 'neopositivismo de dados'” (pp. 107-108, grifo nosso), o que tem reflexos nos mundos diversos: negocial e acadêmico.

Corroborando esse entendimento, Sérgio Amadeu da Silveira (2018) afirma que "as plataformas se alimentam de dados pessoais que são tratados e vendidos em amostras com a finalidade de interferir, organizar o consumo e as práticas dos seus clientes" (p. 35). Silveira (2018) observa que os próprios usuários produzem os conteúdos, que são disponibilizados nos espaços virtuais, todavia, concomitantemente, eles "entregam os seus dados pessoais e seus metadados de navegação para os donos desses serviços" (p. 35), de forma que o capitalismo informacional pode ser entendido como "capitalismo de vigilância", assim nomeado por Shoshana Zuboff (2018). Em síntese, Silveira (2018) destaca que "a grande concentração das atenções e do dinheiro dos demais segmentos da economia nas plataformas se dá porque elas conseguem modular as percepções e os comportamentos em escala inimaginável até a sua existência" (p. 35).

De fato, até pouco tempo, não se poderia imaginar o desenvolvimento de comunicação ou comércio virtual nos moldes ora desenvolvidos. No entanto, em que pese a importância das plataformas e de mídias, bem assim a facilitação que elas permitem no dia a dia, o 'olhar de dados' não pode deixar passar ilesa a influência e controle que as mídias impõem aos seus usuários, ainda que esse controle seja imperceptível ou acobertado por concordâncias daqueles que simplesmente aceitam as regras impostas para utilização de sistemas, sem sequer ler o conteúdo dos ditos contratos de uso.

No original: "[... platforms are digital infrastructures that enable two or more groups to interact." (SRNICEK, 2016, p. 43). 
Esse controle passa, então, a ser evidenciado quando se faz uso constante de determinada plataforma ou serviço digital. A sensação de vigilância passa a ser cada vez maior e transparece um certo temor pelo cerceamento da liberdade e manipulação imperceptível do livre-arbítrio, pela restrição a informações pessoais e pela violação da 'privacidade', direitos que não estão sendo respeitados no mundo virtual.

\section{O CAPITALISMO DE VIGILÂNCIA DE SHOSHANA ZUBOFF E OS DIREITOS FUNDAMENTAIS}

Os dados são, indubitavelmente, os recursos que as empresas de tecnologia buscam para explorar e monetarizar, com a finalidade de obter lucro. Reportando-se a um estudo acerca de big data, conduzido pela Casa Branca, quanto à produção de mais e mais dados acerca dos indivíduos e sobre o controle desses dados, Shoshana Zuboff (2018) aponta para a importância da tecnologia e defende que o big data deve ser estudado em sua origem, ou seja, no social.

Zuboff (2018) caracteriza o big data como "componente fundamental de uma nova lógica de acumulação profundamente intencional e com importantes consequências" (p. 18), que a autora designou "capitalismo de vigilância". Ela explica que essa nova versão de capitalismo busca prever e modificar o comportamento humano e, a partir daí, produzir receitas e controlar o mercado. As relações sociais podem ser alvo de exploração financeira, cujo projeto se funda "na indiferença formal em relação às populações que conformam tanto sua fonte de dados quanto os seus alvos finais" (Zuboff, 2018, p. 18).

A autora aponta para um ambiente intelectual opaco, sem teorias claras, que apresenta "a transformação da cotidianidade em estratégia de comercialização; o ofuscamento das divisões; a natureza da empresa e sua relação com as populações" (Zuboff, 2018, p. 19). Para ela, o capitalismo, apesar de manter a lógica de acumulação, variou ao longo dos tempos com o intuito de manter a demanda e atingir seus objetivos. Ela cita Thomas Piketty para explicar as variantes do capitalismo e novas formas de organizações a atuar no mercado, esclarecendo que o sistema capitalista passou pela produção em massa, pelo capitalismo financeiro até chegar ao capitalismo de vigilância, na civilização da era da informação, em que as pessoas estão hiperconectadas.

Shoshana Zuboff (2018) cita a empresa Google como "pioneira do big data" e, com a popularidade de seu serviço de busca, também "foi a pioneira na lógica de acumulação mais ampla que denominou de "capitalismo de vigilância", para qual big data é tanto uma condição quanto uma expressão" (pp. 24-25, grifo no original). Ela explica que outras empresas se valem do mesmo modelo. No entanto, a Google desenvolveu sistemas que a colocaram no topo do pódio quando se trata de extrair dados, ainda que isso tenha lhe custado acordos milionários e pagamento de multas "que representam um investimento negligenciável para um retorno significativo" (Zuboff, 2018, p. 30). 
O acesso à world wide web (www) deve ser reconhecido como direito humano e fundamental (Shandler $\&$ Canetti, 2019). A rede mundial de computadores é hoje um instrumento indispensável de acesso ao conhecimento humano, havendo de ser, por isso mesmo, universal, um direito de todos. O próprio economista chefe da Google, Hal Varian, reconheceu que "a pessoa mais inteligente do mundo atualmente pode muito bem-estar presa atrás de um arado na Índia ou na China. Capacitar essa pessoa - e milhões como ela - terá um impacto profundo no desenvolvimento da raça humana" (Internet access is "a fundamental right", 2010, n. p.) e, para isso poderão ser utilizados dispositivos móveis para acessar "ferramentas educacionais como a Khan Academy" com grande impacto "sobre a alfabetização e a matemática [o que] levará a uma população mundial mais informada e instruída" (Anderson \& Rainie, 2014, n. p.).

Certo é que as pessoas, cada vez mais, passaram a exercer esse 'direito' e, concomitantemente, deixar rastros de suas 'visitas' ("pesquisas do Google, música do iPod, páginas do Facebook, vídeos do YouTube, blogs, redes, comunidades de amigos, estranhos e colegas" (Zuboff, 2018, p. 31)), permitindo a coleta de dados, o "compartilhamento de informações para todos os propósitos, ou mesmo para nenhum" (p. 31), tornando-se, na 'cotidianidade', fonte de big data por meio da "captura de small data, das ações e discursos mediados por computador, de indivíduos no desenrolar da vida prática" (p. 31).

Enfim, todos os 'rastros' se transformam em dados que "são adquiridos, tornados abstratos, agregados, analisados, embalados, vendidos, analisados mais e mais e vendidos novamente" (Zuboff, 2018, p. 32). A autora explica que o fluxo de dados, rotulados de data exhaust pelos tecnólogos, e a lapidação dos resíduos desses dados impediam a monetização ou indenização em caso de eventuais reclamações, colaborando, assim, para o livre comércio dessa nova fonte de capital.

Empresas do segmento, a exemplo da Google - que foi a percursora -, optaram por um modelo de propaganda, que dependia "da aquisição de dados de usuários como matéria-prima para análise e produção de algoritmos que poderiam vender e segmentar a publicidade por meio de um modelo de leilão exclusivo, com precisão e sucesso cada vez maiores" (Zuboff, 2018, p. 32). Esse sucesso reside exatamente na disponibilização de serviços, de forma 'gratuita', mas que têm como finalidade colher dados deixados pelos usuários. Mais usuários produzem mais data exhauts, "que, por sua vez, melhoram o valor preditivo das análises e resultam em leilões mais lucrativos" (Zuboff, 2018, p. 33).

Importante ressaltar, ainda, que essas empresas não se preocuparam com a subjetividade do usuário, mas tão somente com aquilo que podem explorar dessa

6 No original: "[...] educational tools like the Khan Academy [...] This will have a huge impact on literacy and numeracy and will lead to a more informed and more educated world population." (Anderson \& Rainie, 2014 , n. p.). 
subjetividade - captura e conversão em dados -, que será vendido, convertido em propagandas e, ao final, capturado o usuário, agora como cliente de algum produto ou serviço. Assim, "os dados viajam através de muitas fases de produção, apenas para retornar à sua fonte em uma segunda fase de extração em que o objetivo não é lidar com os dados, mas produzir receitas" (Zuboff, 2018, p. 40), em um ciclo repetitivo, que visa a novas transações.

No documentário "O dilema das redes", lançado pelo Netflix ${ }^{7}$, com o slogan "especialistas em tecnologia e profissionais da área fazem um alerta: as redes sociais podem ter um impacto devastador sobre a democracia e a humanidade" (Rhodes E Orlowski, 2020), várias pessoas que trabalharam em redes sociais e empresas de tecnologia (Facebook, Pinterest, Twiter, Instagram, YouTube, Google e suas derivações, etc.) apontaram as facilidades que as ferramentas trouxeram para a vida.

No entanto, mostraram-se preocupadas com os efeitos ocasionados por elas e pelos aparelhos que proporcionam a conexão com a internet. Não apenas isso: também foram enfocados os riscos para a democracia, como as fake news, influência em eleições, polarizações políticas e rupturas de laços sociais. De forma geral, os entrevistados enfatizaram a importância de divulgar o que acontece "por trás das redes", ou seja, "se você não está pagando pelo produto, você é o produto" (Rhodes \& Orlowski, 2020, 13min.). O produto é a atenção do usuário e para isso deve desenvolver funções para prender a atenção pelo maior tempo possível. Tanto a coleta dos dados, como a mudança de padrões de vida, por meio da criação de uma necessidade para o usuário podem afetar profundamente a sociedade: "é a mudança gradual, leve, imperceptível no seu comportamento e percepção que é o produto" (Rhodes \& Orlowski, 2020). Você é o produto! O documentário revela o que a literatura já vinha a demonstrar (Andrejevic, 2014; Arvidsson \& Colleoni, 2012; Jarvis, 2009; West, 2019; Woods, 2018).

Conforme destaca Zuboff (2018), "as receitas dependem de ativos de dados apropriados por meio de ubíquas operações automatizadas" (p. 41), que constituem uma classe de ativos denominada "ativos de vigilância" que "atraem investimentos significativos que podem ser chamados de capital de vigilância" (p. 41) e operam em um novo formato de capitalismo, mais descolado e extravagante, identificado pela autora como "capitalismo de vigilância". É o mercado que negocia 'futuros de humanos', que transformou as empresas de internet nas mais poderosas e bilionárias da história. Todo o comportamento é monitorado e estimulado para atender aos objetivos financeiros dessas empresas. A autora entende que se trata de

uma nova arquitetura [que] configura-se como um ubíquo regime institucional em rede que registra, modifica e mercantiliza a experiência cotidiana, desde o uso de um eletrodoméstico até seus próprios corpos, tudo com vista a estabelecer

A propósito, veja-se "Como a assustadora engrenagem das redes ameaça a saúde e a democracia". Disponível em https://veja.abril.com.br/tecnologia/como-a-assustadora-engrenagem-das-redes-ameacaa-saude-e-a-democracia/. Acesso em: 26 set. 2020. 
novos caminhos para a monetização e o lucro. O Big Other é o poder soberano de um futuro próximo que aniquila a liberdade alcançada pelo Estado de direito. É um novo regime de fatos independentes e independentemente controlados que suplanta a necessidade de contratos de governança e o dinamismo de uma democracia de mercado. O Big Other é a encarnação, no século XXI, do texto eletrônico que aspira abranger e revelar os amplos fatos imanentes de comportamentos econômicos, sociais, físicos e biológicos. (Zuboff, 2018, p. 44)

Os excedentes comportamentais - rotulados como "escape digital", "migalhas digitais", dentre outros -, operam como filtros ideológicos, que camuflam as atividades das referidas empresas, para evitar que suas atividades sejam interrompidas, atividades essas que "começam com a entrega da experiência humana e terminam com a entrega de dados comportamentais à produção baseada em inteligência de máquina" (Zuboff, 2019, p. 13). Tudo isso corrobora a afirmação de que os usuários são o produto a ser explorado pelas plataformas de mídias, nesse novo modelo de capitalismo: o capitalismo de vigilância.

Por outro lado, as pessoas, de forma geral, ainda confiam nas informações que são transmitidas via internet. No entanto, a atuação dos algoritmos direciona as notícias, produtos, ideias, para aquele que acessa determinada plataforma, de acordo com as preferências apuradas por mecanismos próprios, a exemplo da inteligência artificial (IA). Isso faz com que sejam criadas bolhas que limitam a perspectiva do usuário ou desenvolvem uma visão míope acerca de assuntos de seu interesse, criando, por vezes, a polarização em torno de temas polêmicos.

Tristan Harris expôs que as plataformas constroem modelos, com base em algoritmos, para prever as ações dos usuários, baseados nos cliques, curtidas, notícias lidas, interesses em propagandas (Rhodes \& Orlowski, 2020, 18min.21s.). São feitas compilações que criam modelos quase individuais que induzem comportamentos, compras e até sentimentos, por meio de ajustes para promover cada vez mais a utilização das redes (Meier \& Manzerolle, 2019). As plataformas conhecem mais o usuário do que ele próprio, de forma a reafirmar a citação de Arthur C. Clarke, nos idos de 1962, que "qualquer tecnologia avançada é indistinguível da mágica"8 (Foglia, Esteve, Lijtmaer, Paadín, Miró, \& Baucells, 2018).

Nesse ambiente de "capitalismo de vigilância", como, então, garantir o direito fundamental à liberdade?

\section{DIREITOS FUNDAMENTAIS DA PRIVACIDADE E DA LIBERDADE DE EXPRESSÃO SOB RISCO}

As plataformas de mídia tornaram-se parte fundamental no cotidiano das pessoas, interferindo significativamente nos direitos de privacidade e liberdade de expressão. Ao mesmo tempo em que ampliaram o alcance da livre manifestação do pensamento e

8 No original: "Any advanced technology is indistinguishable from magic" (Foglia, Esteve, Lijtmaer, Paadín, Miró, \& Baucells, 2018, n.p). 
possibilitaram uma interação maior e mais dinâmica entre os indivíduos permitiram, também, um acesso inimaginável a dados privados dos usuários.

A pesquisadora sênior do Instituto Dinamarquês de Direitos Humanos, Rikke Frank Jørgensen (2019), a partir de estudos empíricos e declarações das plataformas em que assumiam o compromisso de respeitar os direitos humanos, especificamente sobre a Google e o Facebook, observou que elas "enquadram sua responsabilidade pelos direitos humanos como uma obrigação de proteger os usuários contra o abuso dos governos [...] e enfatizam seus serviços como facilitadores de direitos específicos, principalmente a liberdade de expressão"9 (p. 167). As empresas reclamam da interferência do governo, como, por exemplo, ao impor o desligamento dos serviços, exigir acesso aos dados dos usuários, entre outros. Porém, ressalta a autora, as plataformas não reconhecem que suas práticas podem, também, prejudicar os direitos dos usuários, principalmente, quando se trata de privacidade (Jørgensen, 2019).

Nicolas Suzor (2018), professor da Faculdade de Direito da Universidade de Tecnologia de Queenslândia e pesquisador-chefe do Centro de Pesquisa em Mídia Digital da Queensland University of Technology (QUT), fez um estudo dos Termos de Serviço contratuais das 14 principais plataformas de mídia social. Diante das preocupações constitucionais quanto à governança das plataformas, o autor propõe "uma estrutura para avaliar a legitimidade da governança de plataformas com base nos valores do Estado de Direito"10 (Suzor, 2018, p. 2), quais sejam o consentimento, a previsibilidade e a justiça processual, com o escopo de garantir a boa governança. Segundo Suzor (2018), os Termos de Serviço contratuais são redigidos de maneira a proteger os interesses comerciais das próprias plataformas. Além disso, a linguagem constitucional ainda não foi adaptada para ser aplicada a esse tipo de esfera privada, o que resulta em maior vulnerabilidade dos usuários:

os usuários têm muito pouco recurso legal para reclamações sobre como as plataformas são governadas. Os usuários são vistos como consumidores que aceitaram voluntariamente os termos de participação em redes privadas. Tendo aceito e adotado esses termos, os usuários são legalmente vinculados por eles. A resposta legal para as preocupações dos usuários sobre a governança de plataformas é, em grande parte: se você não gosta, vá embora." (Suzor, 2018, p. 3)

9 No original: "frame their human rights responsibility as an obligation to safeguard users against overreach by governments. [...] and emphasize their services as enablers of specific rights, most notably freedom of expression." (Jørgensen, 2019, p. 167).

10 No original: "a framework for evaluating the legitimacy of governance of platforms based on the values of the rule of law" (Suzor, 2018, p. 2).

11 No original: "The result is that users have very little legal redress for complaints about how platforms are governed. Users are thought of as consumers who have voluntarily accepted the terms of participation in private networks. Having accepted and adopted these terms, users are legally bound by them. The legal answer to concerns users have about the governance of platforms is, largely: if you don't like it, leave" (Suzor, 2018, p. 3). 
As plataformas não agem de forma neutra, pois priorizam seus interesses comerciais frente às responsabilidades que deveriam assumir para salvaguardar os direitos dos usuários. Porém, segundo a pesquisa de Rikke Frank Jørgensen (2019) o discurso que essas empresas adotam é o inverso:

Ao contrário de estudos recentes sobre plataformas que enfatizam a forma como o modelo econômico, o design técnico e as políticas da plataforma direcionam as práticas sociais em certas direções, os resultados indicam que a equipe do Facebook e do Google geralmente descrevem seus serviços como plataformas neutras que facilitam as práticas comunicativas entre os usuários, mas têm nenhum papel na curadoria desta comunicação. O processo de codificação é descrito como independente de considerações políticas, e os algoritmos são descritos como ferramentas neutras para fornecer os serviços. ${ }^{12}$ (p. 173)

Na verdade, os Termos de Uso e Serviço são estruturados para isentar as responsabilidades das plataformas: os usuários "concordam com o controle da plataforma como preço de entrada, mas mantêm a responsabilidade pessoal por suas ações"13 (Suzor, 2018, p. 3). Diante desse quadro impera a necessidade de não permitir que os direitos fundamentais dos usuários, como sua privacidade e acesso à informação, sejam submetidos à negociação contratual no ambiente de uma governança privada, a qual se acham excluídos.

Segundo Jørgensen (2019) existem dois modelos de regulamentação: a corregulação e a autorregulação. A primeira se refere à delegação a atores privados, de modo voluntário, parcial ou integral, quanto à implementação e aplicação das normas; já a segunda diz respeito à implementação e à aplicação das normas sem qualquer interferência da esfera pública. Quando se trata de cooperação há, por exemplo, o Código de Conduta da União Europeia (UE) contra discursos ilegais de incitação ao ódio online, criado em 2016, para que as empresas de tecnologias de informação, juntamente com a esfera pública da UE, combatam os discursos de ódio na internet e defendam o direito à liberdade de expressão. Ressalta, também, que as organizações da sociedade civil são essenciais para a "prevenção do aumento da incitação ao ódio em linha [online], mediante a elaboração de discursos alternativos que promovam a não discriminação, a tolerância e o respeito, nomeadamente através de atividades de sensibilização" (Comissão Europeia, 2016, p. 1).

12 No original: "Contrary to recent scholarship on platforms that emphasizes the way the economic model, technical design, and platform policies direct social practices in certain directions, the findings indicate that Facebook and Google staff generally depict their services as neutral platforms that facilitate communicative practices among users but have no role in curating this communication. The process of coding is described as detached from political considerations, and algorithms are described as neutral tools for providing the services." (Jørgensen, 2019, p. 167).

13 No original: "They consent to the platform's control as the price of entry, but they retain personal responsibility for their actions." (Suzor, 2018, p. 3). 
Quanto aos parâmetros para se definir o "discurso de ódio", a fim de que o referido código seja aplicado, utiliza-se a Decisão-Quadro 2008/913/JAI do Conselho da União Europeia, de 28 de novembro de 2008, a qual prioriza combater, pela via penal, manifestações de racismo e xenofobia que constituem violações aos princípios do Estado Democrático de Direito:

1. Os Estados-Membros devem tomar as medidas necessárias para assegurar que os seguintes atos sejam puníveis como infrações penais quando cometidos com dolo:

a) A incitação pública à violência ou ao ódio contra um grupo de pessoas ou os seus membros, definido por referência à raça, cor, religião, ascendência ou origem nacional ou étnica;

b) A prática de algum dos atos a que se refere a alínea a) pela difusão ou distribuição públicas descritos, imagens ou outros suportes.

Segundo a Comissão Europeia (2020), o referido Código de Conduta, de 2016, demonstrou resultados positivos conforme a quinta avaliação publicada em 2020, havendo um aumento de 50\% nas avaliações feitas, no período de 24 horas, dos conteúdos assinalados comparados ao ano de 2016, como também, um aumento de $43 \%$ quanto aos discursos considerados ilegais de incitação ao ódio que foram removidos. Apesar dos bons resultados, "só o Facebook informa sistematicamente aos usuários; todas as outras plataformas têm de introduzir melhorias" (Comissão Europeia, 2020).

Atualmente, as empresas que aderem ao código são Facebook, Microsoft, Twitter e YouTube, Instagram, Google+, Snapchat, Dailymotion e jeuxvideo.com. Porém, Jørgensen (2019, p. 176) evidencia que a equipe de políticas do Facebook e do Google compreendem que seus padrões regulatórios "não podem refletir a lei nacional em cada país onde operam"14, pois seus serviços cobrem várias jurisdições. Nesse sentido, para a autora "a decisão sobre quando sancionar o conteúdo, removê-lo e, por fim, fechar uma conta é uma decisão interna da empresa com base na lógica corporativa que os padrões da comunidade representam"15 (Jørgensen, 2019, p. 176). Além disso, esse acordo entre as empresas de tecnologia da informação e o governo acabam sendo baseadas nas normas legais, mas aplicadas conforme os interesses comerciais das plataformas.

Essas observações merecem a devida atenção no instante em que países como o Brasil têm que lidar com um regime nacional de proteção das informações de seus cidadãos. A Lei Geral de Proteção de Dados (Lei n 13.709, 2018) estabelece uma série de normas que procuram disciplinar o uso das informações pessoais, tanto

14 No original: "cannot reflect the national law in each country where they operate" (Jørgensen, 2019, p. 176).

15 No original: "the decision on when to sanction content, remove it, and ultimately close an account is an internal company decision based on the corporate logic that the community standards represent" (Jørgensen, 2019, p. 176). 
no campo da coleta, quanto do tratamento e transferência de dados internacionais. Cria, ademais, um regime de fiscalização e de responsabilização em linha com as legislações mais modernas sobre o assunto, incluindo elementos com a retificação e a desindexação como formas de promoção dos direitos, inclusive ao esquecimento (Lei no 13.709, 2018). O grande desafio é saber como será sua eficácia. Não bastasse o limite das fronteiras, ainda há um tipo de ambiente regulatório ${ }^{16}$ que, por sua dinâmica, escapa aos mais ágeis sistemas de monitoramento - e mesmo de refinados sistemas de cooperação internacional.

Tenove, Buffie, McKay e Moscrop (2018) asseveram que cidadãos com alfabetização digital têm mais autonomia para verificar a confiabilidade das mensagens divulgadas nas plataformas de mídia, por isso, são menos vulneráveis às manipulações. Além disso, pontuam que os setores, tanto privado quanto público, não têm "medidas ou incentivos adequados para proteger os dados das pessoas"17 (Tenove et al., 2018, p. 37) e que a educação dos jovens merece uma atenção especial. No mesmo sentido, Edilene Lôbo e Pedro Moreira (2019) evidenciam a importância de uma campanha de educação digital dos cidadãos, ainda que seja um processo de longa duração, principalmente, no que diz respeito às políticas de restrição de discurso de ódio, racismo e discriminação das minorias.

Nada se resolverá sem que haja uma reeducação para o mundo digital. Certo, pode não ser um beco sem saída, mas há ainda um horizonte de incertezas pela frente. Os direitos estão em risco. A questão é saber se é possível administrá-los.

\section{CONCLUSÕES}

O advento da internet possibilitou maior conexão entre as pessoas, a qualquer distância, e a propagação de informações de maneira rápida, tornando as relações sociais e o mercado mais dinâmicos. Com a evolução da tecnologia, as atividades do cotidiano - comunicar, comprar, vender, trabalhar, estudar - foram adaptadas, para trazer mais comodidade, interação, segurança e acesso às informações, para as pessoas e empresas.

O mundo digital impôs às pessoas vigilância constante como condicio sine qua non para utilização dos serviços fornecidos pelas empresas de tecnologia da informação. Ligado a cultura de vigilância, iniciou-se o processo de financeirização dos dados dos usuários, extraídos e analisados pelas plataformas de mídia para comercializá-los. O acúmulo massivo de dados, os Big Data, passou a instrumentalizar o lucro para essas

\footnotetext{
16 A propósito, a pesquisa National Comprehensive Data Protection/Privacy Laws and Bills 2019, de David Banisar (2019), informou que 130 países já adotaram leis de proteção a privacidade de dados, informações pessoais físicas e digitais, por órgãos públicos e privados e que quase 40 países têm projetos de lei ou iniciativas pendentes.

17 No original: "[...] measures or adequate incentives to protect people's data." (Tenove et al., 2018, p. 37).
} 
empresas. A monetização dos dados como forma de capital, então, é a base do capitalismo de vigilância.

A comercialização de dados pessoais dos usuários, a disseminação e circulação sem controle de informações, com o intuito de enganar e de manipular as pessoas, que essas plataformas possibilitaram, violam os direitos fundamentais à autodeterminação, à privacidade, à liberdade de expressão e ao acesso a informações verídicas. A cada dia se torna mais urgente a regulamentação ou edição de medidas legislativas para limitar os poderes dessas empresas, com finalidade de preservar o constitucionalismo democrático. O grande problema é que uma regulamentação analógica parece não dar conta dos riscos digitais.

Não há uma única solução para os problemas que plataformas digitais trouxeram. Contudo, é fundamental que as propostas apresentadas estejam de acordo com os princípios da Constituição de cada ordenamento jurídico, bem como não violem os direitos os quais se propõe a defender, equilibrando a liberdade de expressão sem incorrer em censura. Pode ser viável, embora ainda se mostre duvidosa em seu efeitos práticos, a adoção de alguns instrumentos como a retificação - correção devido a decisão judicial, pedido de um indivíduo, ou exercício do dever de jornalista - e a desindexação - retirada de sites de conteúdos enganosos -, para garantia do acesso a informações verdadeiras e proteção da livre manifestação do pensamento; a regulamentação relativa a proteção dos dados, impondo às empresas mais transparência quanto à utilização dos dados dos usuários. O Brasil seguiu essa linha com a Lei Geral de Proteção de Dados.

O futuro é nebuloso, se não houver uma guinada no processo de conhecimento do fenômeno e das maneiras de lidar com o ferramental adequado. Tudo passa pela educação digital. Apesar de ser uma solução com eficácia a longo prazo, se faz necessária para a emancipação dos usuários no meio digital, promovendo mais segurança, conscientização e liberdade.

\section{REFERÊNCIAS}

Anderson, J. e Rainie, L. (2014). Digital Life in 2025. Pew Research Center. Internet E Technology. https:// www.pewresearch.org/internet/2014/03/1 1/digital-life-in-2025/

Andrejevic, M. (2014). Free Lunch' in the Digital Era: Organization is the New Content. No L. McGuigan, e V. Manzerolle (eds.), The Audience Commodity in the Digital Age: Revisiting a Critical Theory of Commercial Media. (pp. 193-206). Peter Lang.

Arvidsson, M. e Colleoni, E. (2012). Value in Informational Capitalism and on the Internet. The Information Society, 28(3), 135-150.

Banisar, D. (2019). National Comprehensive Data Protection/Privacy Laws and Bills 2019. Privacy Laws and Bills. https://dx.doi.org/10.2139/ssrn.1951416

Binswanger, H. C. (2011). Dinheiro e magia: uma crítica da economia moderna à luz do Fausto de Goethe. Zahar. 
Comissão Europeia. (2020). Código de Conduta da UE para a luta contra os discursos ilegais de incitação ao ódio em linha continua a produzir resultados. Comissão Europeia. https://ec.europa.eu/commission/ presscorner/detail/pt/ip_20_1134

Comissão Europeia. (2016). Código de Conduta da União Europeia contra discursos ilegais de incitação ao ódio em linha. Comissão Europeia. https://ec.europa.eu/info/policies/justice-and-fundamental-rights/ combatting-discrimination/racism-and-xenophobia/eu-code-conduct-countering-illegal-hatespeech-online_en

Conselho da União Europeia. (2008, 28 de Novembro). Decisão-Quadro 2008/913/JAI do Conselho, relativa à luta por via do direito penal contra certas formas e manifestações de racismo e xenofobia. https:// eur-lex.europa.eu/legal-content/PT/TXT/?uri=LEGISSUM\%3Al33178

Foglia, E., Esteve, F., Lijtmaer, L., Paadín, L., Miró, O. M. e Baucells, R. M. (2018). Any sufficiently advanced technology is indistinguishable from magic. CCCBLAB. Cultural Research and Innovation. https://bit. ly/2OleXQj

Grohmann, R. (2019). Financeirização, midiatização e dataficação como sínteses sociais. Mediaciones de la Comunicación, 14(2), 97-117.

Harari, Y. N. (2016). Homo Deus: Uma breve história do amanhã. (P. Geiger, trad.). Companhia das Letras.

Indolia, S., Goswami, A. K., Mishra, S. P. e Asopa, P. (2018). Conceptual understanding of convolutional neural network-a deep learning approach. Procedia computer science, 132, 679-688.

BBC News. (2010, March 8). Internet access is 'a fundamental right'. https://news.bbc.co.uk/2/hi/8548190.stm

Jarvis, J. (2009). What Would Google Do? HarperCollins.

Jørgensen, R. F. (2019). Rights Talk: In the Kingdom of Online Giants. No R. F. Jørgensen. (Ed.), Human rights in the age of platforms. (pp. 163-187). MIT Press.

Kitchin, R. (2017). Thinking critically about and researching algorithms. Information, Communication \& Society, 20(1) 1-16. https://bit.ly/313KzWE

Brasil. (2018, 14 de Agosto). Lei no 13.709. Seção 1. Diário Oficial 15/08/2018. p. 59. https://www.planalto. gov.br/ccivil_03/_ato2015-2018/2018/lei/L13709.htm

Lôbo, E. e Moreira, P. H. C. (2019). Fake News e autenticidade das eleições brasileiras. No A. A. Oliveira, L.G. da Silva, M. F. de Castro e R. Beçak. (Coords.). Teoria da democracia e da Filosofia do Estado e Direito constitucional. (pp. 285-301). Prensas de la Universidad de Zaragoza.

Lôbo, E., \& Bolzan de Morais, J. L. (2021). New technologies, Social Media and Democracy. Opinión Jurídica, 20(41), 253-274. https://doi.org/10.22395/ojum.v20n41a9.

Machado, D. (2018). A modulação de comportamento nas plataformas de mídias sociais. No J. Souza, R. Avelino e S. A. da Silveira. (Orgs.). A sociedade de controle: manipulação e modulação nas redes digitais. (pp. 47-69). Hedra.

Meier, L. M., Manzerolle, V. R. (2019). Rising tides? Data capture, platform accumulation, and new monopolies in the digital music economy. New Media \& Society, 21(3), 543-561.

Rhodes, L. (Produtora) \& Orlowski, J. (Diretor). (2020). O dilema das redes [série de televisão]. Netflix.

Redes neurais artificiais. (n. d.). Consultado em 30 de setembro de 2020. https://bit.ly/3eteiqO 
Sadowski, J. (2019). When data is capital: datafication, accumulation, and extraction. Big Data \& Society. https://doi.org/10.1177\%2F2053951718820549

Shandler, R., Canetti, D. (2019). A Reality of Vulnerability and Dependence: Internet Access as a Human Right. Israel Law Review, 52(1), pp. 77-98.

Silveira, S. A. (2018). A noção de modulação e os sistemas algorítmicos. No J. Souza, R., Avelino e S. A. da Silveira. (Orgs.). A sociedade de controle: manipulação e modulação nas redes digitais. (pp. 31-46). Hedra.

Srnicek, N. (2016). Platform Capitalism. Polity.

Suzor, N. (2018). Digital constitutionalism: Using the rule of law to evaluate the legitimacy of governance by platforms. Social Media+Society, 4(3). https://journals.sagepub.com/doi/10.1177/2056305118787812

Tenove, C., Buffie, J., McKay, S., e Moscrop, D. (2018). Digital Threats to Democratic Elections: How Foreign Actors Use Digital Techniques to Undermine Democracy. Centre for the Study of Democratic Institutions. The University of British Columbia. https://dx.doi.org/10.2139/ssrn.3235819

Van der Zwan, N. (2014, January). Making sense of financialization. Socio-Economic Review, 12(1), 99-129. https://doi.org/10.1093/ser/mwt020

West, S. M. (2019). Data Capitalismo: Redefining the logics of surveillance and privacy. Business and Society, 58(1), 20-41.

Woods, H. S. (2018). Asking more of Siri and Alexa: feminine persona in service of surveillance capitalism. Critical Studies in Media Communication, 35(4), 334-349.

Zuboff, S. (2018). Big other: capitalismo de vigilância e perspectivas para uma civilização de informação. No F., Bruno, B., Cardoso, B., M. Kanashiro, M., L., Guilhon e L., Melgaço, L. (Orgs.). Tecnologias da vigilância: perspectivas da margem. (pp. 17-68). (H.M., Cardozo, et al., trads.). Boitempo.

Zuboff, S. (2019). "We make Them Dance": Surveillance Capitalism, The Rise of Instrumentarian Power, and the Threat to Human Rights. No R. F., Jørgensen. (Ed.), Human rights in the age of platforms. (pp. 3-51). MIT Press. 